\title{
Asian Mouse Mutagenesis Resource Association (AMMRA): mouse genetics and laboratory animal resources in the Asia Pacific
}

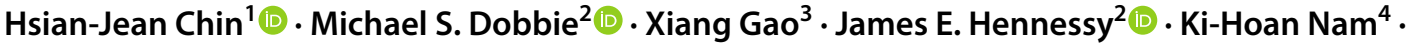

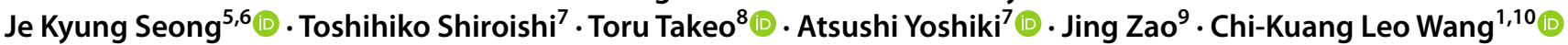

Received: 1 July 2021 / Accepted: 29 August 2021 / Published online: 5 September 2021

(c) The Author(s), under exclusive licence to Springer Science+Business Media, LLC, part of Springer Nature 2021

\begin{abstract}
The Asian Mouse Mutagenesis Resource Association (AMMRA) is a non-profit organization consisting of major resource and research institutions with rodent expertise from within the Asia Pacific region. For more than a decade, aiming to support biomedical research and stimulate international collaboration, AMMRA has always been a friendly and passionate ally of Asian and Australian member institutions devoted to sharing knowledge, exchanging resources, and promoting biomedical research. AMMRA is also missioned to global connection by working closely with the consortiums such as the International Mouse Phenotyping Consortium and the International Mouse Strain Resource. This review discusses the emergence of AMMRA and outlines its many roles and responsibilities in promoting, assisting, enriching research, and ultimately enhancing global life science research quality.
\end{abstract}

\section{Introduction}

The Asia-Pacific region is home to a large and increasing number of world-leading mouse genetics research centers and facilities. However, most of the mouse resources are in North America and Europe decades ago. The shortage of mutant mouse resources limited the development of biomedical research in Asia. To (i) guard against the inefficiencies of a disjointed and limited provision of genome engineered animals, (ii) overcome logistic challenges, and (iii) to maximize the opportunities for valuable scientific collaboration across the region, a coordinated approach to the delivery of services and access to technology platforms was proposed. Working together in a concerted and allied manner enables technology developments to be rapidly deployed and resources readily shared across this culturally diverse and geographically dispersed region.

Hsian-Jean Chin, Michael S. Dobbie, Xiang Gao, James E. Hennessy, Ki-Hoan Nam, Je Kyung Seong, Toshihiko Shiroishi, Toru Takeo, Atsushi Yoshiki, Jing Zao and Chi-Kuang Leo Wang contributed equally to this work.

Chi-Kuang Leo Wang

cklwang@ust.hk

1 National Laboratory Animal Center (NLAC), NARLabs, Taipei, Taiwan

2 Phenomics Australia, John Curtin School of Medical Research, Australian National University, Canberra, ACT, Australia

3 National Resource Center of Mutant Mice (NRCMM), Nanjing Biomedical Research Institute, Nanjing University, Nanjing, China

4 Laboratory Animal Resource Center, Korea Research Institute of Bioscience and Biotechnology (KRIBB), Daejeon, Korea
5 College of Veterinary Medicine, Seoul National University, Seoul, Korea

6 Korea Mouse Phenotyping Center (KMPC), Seoul, Korea

7 RIKEN BioResource Research Center (BRC), Tsukuba, Japan

8 Center for Animal Resources and Development (CARD), Institute of Resource Development and Analysis, Kumamoto University, Kumamoto, Japan

9 GemPharmatech Co. Ltd, Nanjing, China

10 The Hong Kong University of Science and Technology, Hong Kong, Hong Kong 


\section{History of AMMRA}

Aiming to decipher the functional annotation of all mammalian coding genes, several key institutes and facilities for mouse genetic research across Europe and North America formed the International Mouse Knockout Consortium (IKMC) in 2006. To foster and coordinate the contribution of Asian countries to these world-wide efforts, the Asian Mouse Mutagenesis Resource Association (AMMRA) was formed in the same year including representatives from leading research centers in China, Japan, Korea, Taiwan, and Singapore (Table 1). With the mission "to promote mouse mutagenesis projects and to facilitate access to mouse resources in Asia", AMMRA maintains the policies and charters of the association (such as ongoing strategy, membership, and governance) to further enhance effective collaboration for generating, preserving, and distributing mouse resources among members. AMMRA brings together the strength of mouse resources in Asian Pacific, promotes the usage of mutant mouse by talent cultivation, and goes along with the global developing trend by connected with global organizations.

Since its foundation, the AMMRA membership has grown and the current 10 member organizations are presented in Fig. 1. The members of AMMRA are from regional major archives. Their agreement to share and train stems from their devotion to assist the scientific community, and to help promote resource sharing and training. Through these specialist centers, scientists can benefit from regionwide sharing of resources and also regular opportunities for in-person sharing of knowledge and expertise. Meanwhile, members can serve as local representatives of other members to provide support for cryo-recovery and regional logistics issues. AMMRA has played a crucial role achieving, through the governments of China, Japan, Korea, Australia, and Taiwan, specific funding of national infrastructure for mouse model development and application. These programs significantly promoted life science research, encouraged mouse genetics and human genome research, and accelerated preclinical studies making use of mouse models.

\section{AMMRA, IMPC and AMPC}

In 2006, IKMC was formed by members in the EU, USA, and Canada. Its initial purpose was to perform knockout phenotyping and this was later expanded to include entire mouse phenotyping. In 2009, Dr. Shigeharu Wakana at RIKEN and Prof. Je Kyung Seong at Seoul National University first discussed the need to establish an Asian initiative. This idea was promoted in more detail, when AMMRA sought ways to reshape the structure of the association. AMMRA members particularly began to discuss better utilization of the existing phenotyping platforms in China, Japan, Korea and Taiwan for additional functional screening in the 5th AMMRA premeeting in Hong Kong. These discussions eventually led to the inauguration of the Asian Mouse Phenotyping Consortium (AMPC) at Taipei in 2010. All large phenotyping centers in Asia, including MARC/NRCMM in China, IDB of Fudan University in China, KRIBB in Korea, RIKEN BRC in Japan, and NLAC NARLabs in Taiwan joined AMPC as
Table 1 AMMRA meetings and milestones

\begin{tabular}{ll}
\hline Year & Events \\
\hline 2006 & $\begin{array}{l}\text { Asia Mouse Mutagenesis and Resource Symposium, Shanghai, China } \\
\text { AMMRA founded by scientists from China, Korea, Japan, Taiwan, and Singapore }\end{array}$ \\
& Founding president: Dr. Kenichi Yamamura, CARD, Japan \\
2010 & Asian Mouse Phenotyping Consortium (AMPC) launched by China, Japan, Korea, and Taiwan \\
2011 & 2nd president: Dr. Xiang Gao, NRCMM, China \\
2012 & First AMMRA workshop launched \\
2013 & First AMMRA annual report published \\
2014 & 3rd president: Dr. Yuichi Obata, RIKEN BRC, Japan \\
2016 & 4th president: Dr. Hyoung-Chin Kim, KRIBB, Korea \\
2017 & 5th president: Dr. Michael Dobbie, Phenomics Australia, ANU, Australia \\
2019 & 6th president: Dr. Chi-Kuang Leo Wang, NLAC NARLabs, Taiwan \\
2020 & AMMRA participates in the Global Mouse Models for COVID-19 Consortium (GMMCC) to \\
2021 & 5upport research fighting against the COVID-19 crisis \\
& 7th president: Prof. Je Kyung Seong, SNU, KMPC, Korea
\end{tabular}

AMMRA Asian Mouse Mutagenesis and Resource Association, CARD Center for Animal Resources and Development, NRCMM National Resource Center of Mutant Mice, KRIBB Korea Research Institute of Bioscience and Biotechnology, NLAC NARLabs National Laboratory Animal Center, National Applied Research Laboratories, RIKEN BRC RIKEN BioResource Research Center, KMPC Korea Mouse Phenotyping Center, $A N U$ Australian National University, $S N U$ Seoul National University 


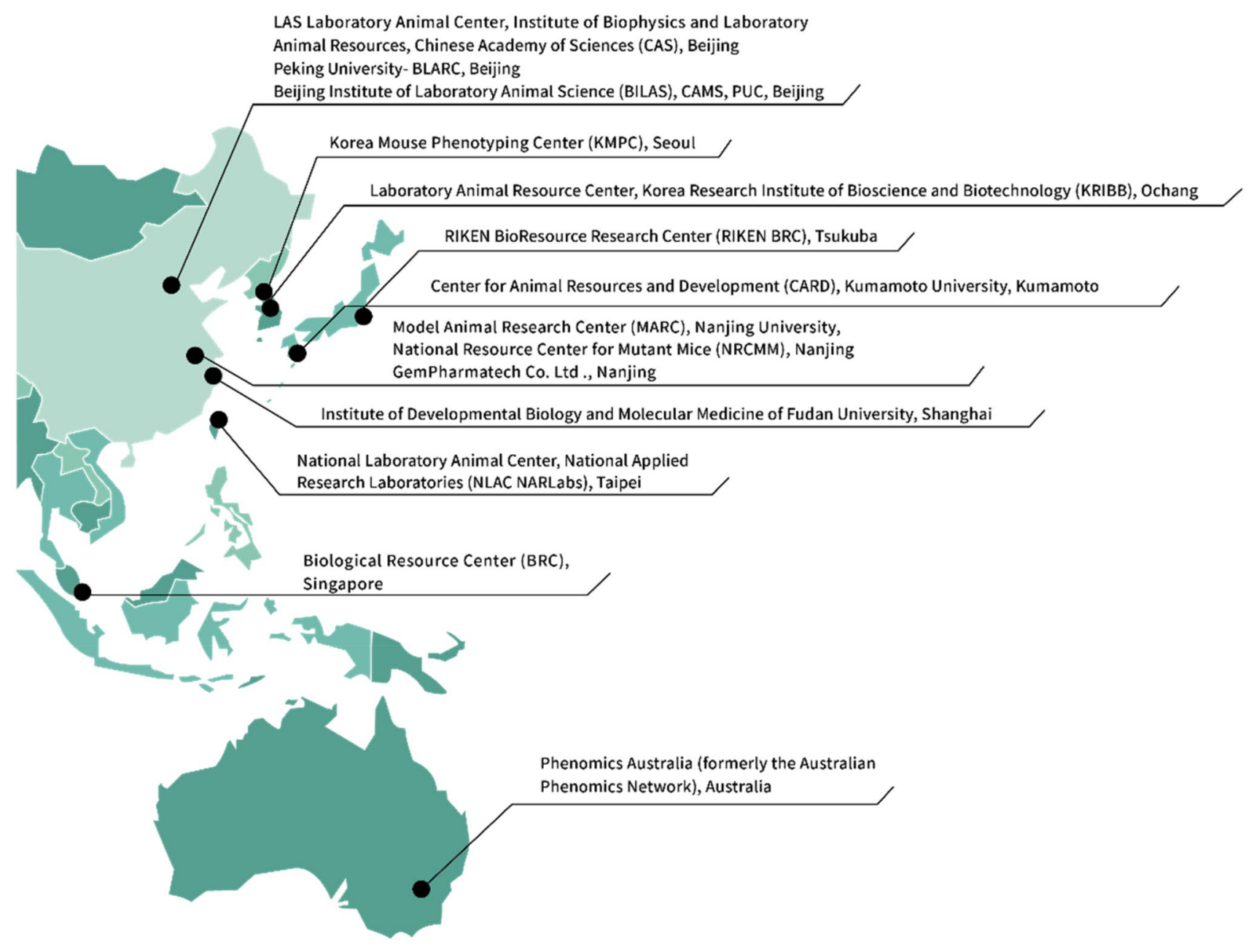

Fig. 1 Current AMMRA members

a founding member, and then KMPC in Korea, Phenomics Australia (formerly the Australian Phenomics Network) in Australia, and TMC in Taiwan later became a member of AMPC. With help from members of AMPC, various mouse phenotyping initiatives have been underway, demonstrating the value of functionally analyzing these mouse models. Under the cooperative action on the mouse phenotyping, AMPC has pursued to organize strategies and platforms for phenotyping and informatics. AMPC also has eagerly collaborated with international efforts such as the International Mouse Phenotyping Consortium (IMPC), which kicked off at NIH on September 23rd, 2011 aiming to systematically phenotype KO strains generated using ES cell lines developed by IKMC.

\section{Genetic engineered mouse resources in Asia-Pacific}

Coinciding with the establishment of AMMRA has been a four-fold growth in mouse model related publications in Asia from 2005 to 2020, and publications from AMMRA member countries now represent over $50 \%$ of the global total, indicating the high influence of the mouse studies in Asia-Pacific (Fig. 2).

Most AMMRA members are registered in the International Mouse Strain Resource (IMSR), a searchable online database for international mouse resources. Complementing established mouse resources available in Europe, North America and Japan, and through the progression of regional repository and large-scale production projects in AMMRA institutes, the number of genetically modified mouse models available in Asia has increased rapidly. For example, GemPharmatech, a biotech company associated with National Resource Center for Mutant Mouse (NRCMM) of China, has developed more than 7500 floxed mouse strains since 2018 . 


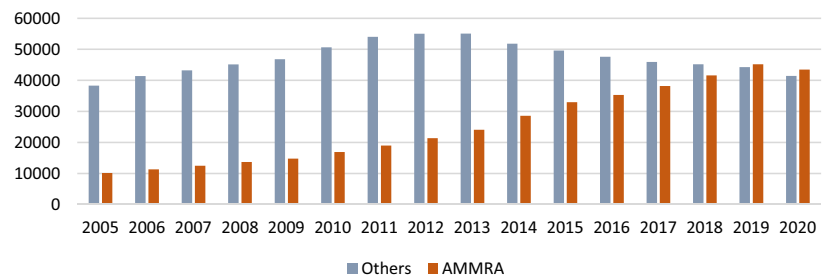

Fig. 2 Publication related to mouse study. PubMed search using "mouse" and affiliation "region" as keywords, from 2005 to 2020. AMMRA: region=Japan, Korea, China, Australia, Singapore, and Taiwan. Others: PubMed search using "mouse" minus PubMed search using "mouse' and AMMRA regions

Combined with the effort of NRCMM, more than 17,000 new genetic modified mouse models were generated within three years and established the institute as the second largest repository in the world. Currently, AMMRA members maintain approximately $40 \%$ of the mouse resources (sperm, embryo, and live animal) in the world, as a major hub of resource archiving and distribution (Fig. 3). Furthermore, RIKEN BRC has also distributed 45,000 mouse resources including genetically modified mouse strains in the form of live animal, frozen sperm or embryos to unique 7500 domestic and overseas scientists at over unique 1500 universities/ institutions around the world.

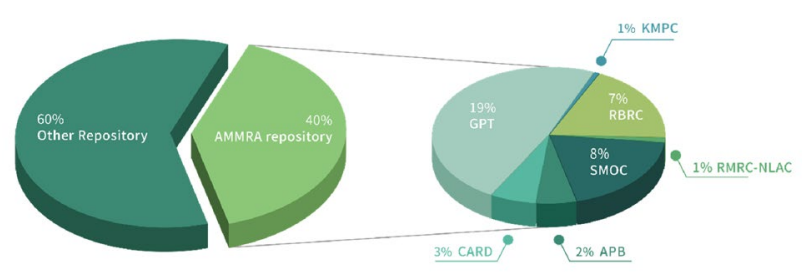

\begin{tabular}{|c|c|c|}
\hline Repository & Region & Mouse Strains \\
\hline Australian Phenome Bank (APB) & Australia & 1,907 \\
\hline $\begin{array}{l}\text { Center for Animal Resources and } \\
\text { Development (CARD) }\end{array}$ & Japan & 2,409 \\
\hline GemPharmatech (GPT) & China & 17,010 \\
\hline $\begin{array}{l}\text { Korea Mouse Phenotyping Center } \\
\text { (KMPC) }\end{array}$ & Korea & 293 \\
\hline $\begin{array}{llll}\text { RIKEN } & \text { BioResource } & \text { Research } & \text { Center } \\
\text { (RBRC) } & & & \\
\end{array}$ & Japan & 5,505 \\
\hline $\begin{array}{l}\text { National Applied Research Laboratories } \\
\text { (RMRC-NLAC) }\end{array}$ & Taiwan & 351 \\
\hline Shanghai Model Organisms Center (SMOC) & China & 5,481 \\
\hline $\begin{array}{l}\text { Other Repository ( } 22 \text { repositories listed in } \\
\text { IMSR www.findmice.org) }\end{array}$ & $\begin{array}{l}\text { USA,Canada, } \\
\text { Germany, } \\
\text { France, UK } \\
\text { etc. }\end{array}$ & 43,472 \\
\hline
\end{tabular}

Fig. 3 Mouse Resources in Asia-Pacific

\section{Center for Animal Resources and Development (CARD), Kumamoto}

CARD was established as a hub research and resource center of genetically engineered mice at Kumamoto University in 1998 (Nakagata and Yamamura 2009; Nakagata 2010). CARD plays an important role in the leading core facility of production, phenotyping analysis, cryopreservation, and supply of genetically engineered mice. In 2013, CARD started to provide the service of mouse phenotyping system as Kumamoto Mouse Clinic. CARD Mouse Bank archives more than 2400 strains of genetically engineered mice and publishes information of the available mouse lines in CARD Resource Database (CARD R-Base, http://cardb.cc.kumam oto-u.ac.jp/transgenic/). We continuously improved the system of mouse banking using mouse reproductive technology (Takeo et al. 2020). A robust system of CARD protocols was established to efficiently preserve sperm and embryos, produce mutant mice, and expand mouse colonies. To share our experience and techniques, we have organized CARD Mouse Reproductive Technology Workshops in Japan and abroad (China, Taiwan, Korea, Singapore, Spain, France, and USA) since 2000. Additionally, the training of specialists in reproductive technology is an important mission of CARD.

\section{GemPharmatech Co. Ltd. (GPT)}

Established in 2017, GemPharmatech (GPT) is a global biotech company dedicated to providing a one-stop-shop solution for in vivo biomedical research using genetically engineered mouse models. The GPT team has 20 years of experience in generating and breeding disease models and conducting preclinical efficacy studies for both academic and industrial clients. We are dedicated to our long-term mission of providing world class mouse models and preclinical services to facilitate an efficient and rapid advancement of science to treat human diseases. We believe that the next 20 years will bring forth amazing medical breakthroughs. The company has a comprehensive service platform which includes humanized mouse models, customized model generation, germ-free mice service, breeding and husbandry and numerous disease models. The ACE2 humanized mice have been broadly applied for fighting COVID-19 pandemic (Qiao et al. 2021). Our ambitious knockout all platform (KOAP) is currently generating knockout and conditional knockout mice for all protein coding genes. In addition, we can perform, phenotyping, drug development and efficacy testing.

Currently, GPT holds more than 17,000 strains of mice. Our mice have been distributed to thousands of customers throughout world, including universities, research institutes, 
hospitals, CROs, biotech companies and pharmaceutical companies. We are operating in five cities in China, including Nanjing, Beijing, Foshan, Chengdu and Changzhou, with more than 100,000 cages of AAALACI accredited SPF facilities. GPT also has a fully owned company located in the United States.

\section{Institute of Developmental Biology and Molecular Medicine (IDM), Shanghai}

The Institute of Developmental Biology and Molecular Medicine (IDM) was established in 2001 at Fudan University, Shanghai, China. On a mission to conduct internationally competitive research and train top scientists, IDM is a pioneer in China for specific pathogen free (SPF) animal model practice. IDM established the piggyBac transposon system in mammals and developed the PBmice library containing about 5000 mutant strains, serving as a precious resource for global biomedical community. Last year, a new $\sim 10,000 \mathrm{~m}^{2}$ facility with a capacity of 25,000 cages and multiple specialized function sections came into service at IDM, enabling better supply of genetically modified mice and phenotypic analysis.

The current research interests at IDM focus on developmental biology, immunology, and metabolism, with emphasis on obesity, cancer, and autoimmune diseases. IDM scientists are incorporating collaborative and cuttingedge technologies, such as multi-omics, to disclose genetic basis and molecular mechanism of diseases. With these powerful tools and our animal resources, it became feasible for the first time to identify proper disease models not by a few visible markers but deep molecular-scale analysis, which greatly accelerates pathology investigation and drug development. Moreover, to decipher the genomic cause of human diseases and uncover more potential drug targets, a large-scale forward genetics study on metabolic and immunological phenotypes is being planned.

\section{Korea Mouse Phenotyping Center (KMPC)}

In 2013, the Korea Mouse Phenotyping Center (KMPC) was established and funded by the Ministry of Science and ICT in South Korea. It is a nationwide research infrastructure to standardize phenotyping mouse disease models across Korea as well as to provide global researchers with genetically engineered mouse model phenotype analysis. In 2016, KMPC created Mouse One Portal (MOP, https://mouse info.kr), a one-stop online platform for mouse resource information. Through MOP, KMPC has produced nearly 300 genetically engineered mouse models and distributed over 100 mouse models to scientists. It has been collecting information of mouse resources and providing approximately 2500 mouse resources to researchers in Korea. In addition to the collection of resources, KMPC has offered representative mouse phenotyping platforms such as metabolic phenotyping, sensory phenotyping, primary phenotyping, in vivo molecular imaging, pathology, and secondary immunophenotyping. KMPC has also actively participated in international communities as an official member of IMPC, AMMRA, AMPC, and GMMCC, providing valuable mouse model information for researchers.

As of Spring 2021, KMPC has two government-funded missions, one is establishing a Model Animal Cluster Program expanded from MOP, and another mission is building infrastructure to study preclinical trials on infectious diseases focusing on COVID-19. Firstly, the Model Animal Cluster Program is an integrated model organism biobank database not only for mouse models but also for other genetically modified organisms (C. elegans, Drosophila, Xenopus, etc.) and core model animals (non-human primates, marmosets, mini pigs, etc.). This biobank cluster will collect all Korean nationwide model animal resources and related information from all designated research centers. KMPC will be the center for this cluster program which governs all the information and runs the new web portal site called Korean Animal Model Archive (KAMA). This grant will be renewed every 5 years. The second government-funded mission is developing treatments and vaccines for COVID19 and new infectious diseases and also to plan and support accelerating drug development programs in preparation for future pandemics. Using various genetically modified mouse models, KMPC has been building an infrastructure for more efficient ways to develop treatments and drugs in preclinical studies. We have supported over 30 different preclinical trials within 7 months. KMPC built an alliance of ABSL-3 facilities in Korea and helped the distribution of research relevant mouse models for ongoing studies. KMPC designed and produced COVID-19 related mouse models in early 2020 and prepared various types of hACE2 transgenic mouse models to help researchers urgently respond to COVID-19. This emergency funding program has been renewed as a new grant called "Building on Infrastructure to Support Preclinical Trials", a 6-year research project starting in 2021. KMPC will be providing mouse resources for infectious disease across the globe.

\section{Korea Research Institute of Bioscience and Biotechnology (KRIBB), Ochang}

KRIBB is the government-funded non-profit research institute dedicated to conduct basic research and development for bioscience and biotechnology, and also meeting the infrastructure needs for Korean research. Since 1985, 
Laboratory Animal Resource Center (LARC) at KRIBB has been carrying out the Maintenance and Conservation Project for Laboratory Animals, mainly on mouse strains, and contributing to the growth of the laboratory animal industries and academia in Korea. The center was also accredited as the Monitoring Subcenter Korea by the International Council for Laboratory Animal Science (ICLAS) and has been providing disease monitoring services for laboratory animal facilities for more than 20 years. In 2019, the center was designated by the Korean government as the only dedicated center for mouse resource as one of the national strategic bio-research resources. Around 150 mouse strains are newly archived in the center every year. Currently, more than 1000 mouse strains are open to researchers for distribution, including around 450 mouse strains which are produced by domestic researchers. Moreover, by participating in the International Mouse Phenotyping Consortium (IMPC) through the Korea Mouse Phenotyping Center (KMPC), the center established a broad-based basic mouse phenotypic analysis system and is providing mouse phenotyping services to research community. The center has been a core institution of mouse resources in Korea by communicating with users domestically and internationally. In addition, to further support future precision medicine in Korea, the center is strengthening its user-oriented mouse model production ability. The center will continuously take the lead in improving the mouse research environment in Korea.

\section{Laboratory Animal Resources, Chinese Academy of Sciences (LAR/CAS), Beijing}

The Laboratory Animal Resources, Chinese Academy of Sciences (LAR/CAS) was established in 2006 and comprises 17 institutional laboratory animal facilities across China. Currently the LAR/CAS has five regional branches in Beijing, Shanghai, Hubei, Guangdong and Yunnan provinces. Among those facilities, three national centers were named for non-human primates, rodent and zebrafish research, respectively. In 2016, the LAR/CAS started to launch a national integrative animal mutant database (http://www.lar. ac.cn). By the end of 2020, the website had implemented data exchange services for tens of thousands of animal strains across China. The LAR/CAS provides routine technical services for screening and phenotyping mutant animal models. The LAR/CAS facilities also organize and coordinate various technical training services for both local and international laboratory animal users.

Especially, by combining single-cell sequencing and bioinformatics analysis, LAR/CAS have established a candidate pool of potential novel candidates of lncRNAs and circRNAs. Through mouse phenotypic screening, we have generated more than 50 mouse lines per year and characterized a few novel lncRNAs and circRNAs playing essential roles in organogenesis, embryogenesis, modulation of immune system and tumorigenesis (Wang et al. 2018; Liu et al. 2020, 2021). These mouse data demonstrate that lncRNAs and circRNAs are essentially invaluable targets for next-phase genome engineering in IMPC which should require multinational international efforts.

\section{National Laboratory Animal Center (NLAC), NARLabs, Taipei}

National Laboratory Animal Center (NLAC) is a member of National Applied Research Laboratories (NARLabs), a non-profit organization funded by the Ministry of Science and Technology (MOST), Taiwan. NLAC was established in 1994 as the first National Laboratory for animal resources in Taiwan. The mission of NLAC is to be the foundation and key platform for biomedical research and facilitate the development of biotechnology industry. NLAC is dedicated to the generation, archiving, and sharing of GM mouse and rat models. NLAC founded the Rodent Mouse Resource Center (RMRC) in 2009, the first rodent repository in Taiwan, and an international core center in deposition, archive, and distribution. RMRC connects with existing NLAC services, providing diversified animal resources and testing services. Integrated service platforms include cryopreservation, rederivation, assisted reproductive technology, health monitoring, phenotyping, breeding and housing, and preclinical efficacy testing services. RMRC is now the most important repository in Taiwan, archiving more than 2700 strains from the local scientists, with 396 strains registered in IMSR for international sharing.

To further enrich the GM resources in Taiwan, NLAC initiated the Genetic Engineered Murine Model Services (GEMMS) project in 2010. GEMMS aims to strengthen research through efficient murine model production and utilization. GEMMS specializes in genetic engineering for strategic model creation. GEMMS services can sustain high flexibility on injected material (DNA and RNA), species (mice and rat), and transgene size (from hundred bp (RNAi) to hundred $\mathrm{Kb}(\mathrm{BAC}))$. The efficient operation and success led GEMMS become one of the production partners of IMPC in 2014. Thus far, GEMMS has generated around 200 novel conditional knockout, Cre, and reporter mice strains.

\section{National Resource Center of Mutant Mice (NRCMM), Nanjing}

NRCMM was established in 2001 by the Ministry of Science and Technology of China and currently co-managed by Nanjing University and GemPharmatech Co. Ltd (www. 
escience.org.cn). The mission of NRCMM is to promote biomedical research and therapeutic development in China by providing valuable mouse model resources and related services. In the past 20 years, NRCMM has generated more than 15,000 genetically modified mouse stains. Collaboration with Chinese scientists and utilization of these mouse resources have enabled more than 3000 research papers advancing our understanding of complicated diseases. The NRCMM services include repository capabilities, cryopreservation, and the distribution of mutant mice. NRCMM has initiated several projects on standardizing the phenotyping, quality control, cryopreservation and distribution protocols of mutant mice in China. NRCMM is also a member of International Mouse Phenotyping Consortium (IMPC), the purpose of which is to create a comprehensive catalog of mouse gene function. In addition, NRCMM hosts education programs for mouse colony management and mouse genetics studies.

As examples of prominent research impacts, NRCMM generated the first knockout mouse strain in China, and generated the first knockout dog and knockout monkey in the world (He et al. 2008; Niu et al. 2014; Zou et al. 2015).

\section{Phenomics Australia}

Established in 2006 (as the Australian Phenomics Network), Phenomics Australia (https://phenomicsaustralia.org.au) is a founding capability of the Australian Government's National Collaborative Research Infrastructure Strategy (NCRIS) program. Phenomics Australia is an Australian national alliance of research infrastructure facilities hosted by universities and medical research institutes. Phenomics Australia has grown to span nine locations across Australia, providing researchers with specialized infrastructure, research services and technical expertise dedicated to advancing our fundamental understanding of health and disease, and enabling next-generation innovations in healthcare and therapeutic development. The key offerings of Phenomics Australia comprise preclinical model systems and platform technologies including cell-and animal-based functional genomics assays for the investigation of the genetic basis of human disease and disease susceptibility, and the development and testing of new therapeutics. Phenomics Australia's state-of-the-art capabilities and technologies are in increasingly high demand by a growing number of biomedical researchers largely from universities and medical research institutes across Australia and internationally. The Australian Phenome Bank (https://pb.apf. edu.au/phenbank/homePage.html) provides a database and cryobank of approximately 2000 mouse strains (sperm and embryos) for the preservation, protection and distribution of disease models in Australia using internationally-agreed best practice policies, procedures, and protocols.
Phenomics Australia also hosts an unusual and vast biorepository of mice with identified single nucleotide mutations and corresponding exome sequence data in the Missense Mutation Library (MML) (https://databases.apf.edu.au/ mutations/). The MML offers over 500,000 alleles across a total of over 24,000 protein coding genes, effectively representing a saturation mutagenesis resource for the mouse genome. The gene, chromosome, exact location (Ensembl coordinates) and amino acid change or distance from the splice junction are searchable along with a Polyphen2 score and a SIFT mutation prediction analysis, along with rare disease gene associations. Because these are ENU-induced mutations, they afford all the advantages of any viable point mutation, including domain-specific effects and other nuanced alleles. Some mutations may even directly replicate human disease-associated alleles. Furthermore, the MML includes over 22,000 nonsense mutations, representing a possible alternative source of null mutant mouse strains. Mutations can be validated and mice reanimated from the MML upon request.

Complementary capabilities using in vivo and in vitro genome engineering for the creation of a rich portfolio of preclinical models of disease enables researchers to explore the human genome and the genetic and environmental contributions to health and disease. Through a broad platform of characterization capabilities spanning genome sequencing, high-throughput screening and a specialized mouse histopathology services, researchers are able to analyze the functional consequences of genomic variation and determine the utility of potential therapeutics and identify off-target effects.

\section{RIKEN BioResource Research Center (RIKEN BRC), Tsukuba}

RIKEN BRC was established in 2001 and has been designated as the mouse resource core facility (and the backup rat resource facility) for the National BioResource Project, MEXT, Japan. RIKEN BRC has collected, preserved, quality-controlled and distributed valuable mouse resources created mainly in Japan with support of the global research community (Yoshiki et al. 2009; Masuya et al. 2021). Four divisions and three teams at RIKEN BRC have collaborated to participate in AMMRA and IMPC, facilitate dissemination of mouse resources, and enrich the value of the strains with broad-based phenotyping data and high-quality genome information (Takada et al. 2015; Dickinson et al. 2016; Bowl et al. 2017; Karp et al. 2017; Rozman et al. 2018; Lloyd et al. 2020; Tanaka and Masuya 2020) as well as sharing relevant knowledge and technologies with the global community (Masuya et al. 2011; Kobayashi et al. 2018). Moreover, RIKEN BRC provides the domestic research community with a comprehensive phenotype analysis platform referred 
to as the "Japan Mouse Clinic" (Wakana et al. 2009; Kishimoto et al. 2018; Furuse et al. 2019; Matsumura et al. 2020). As a founding member of AMMRA, RIKEN BRC has participated in The Global Mouse Models for COVID-19 Consortium (GMMCC) since February 2020 to challenge urgent global issues on the COVID-19 pandemic and started disseminating information on useful mouse strains for COVID19 research. RIKEN BRC will continue collaboration with AMMRA and other international research centers to expand useful mouse resources to meet the needs of the international research community.

\section{Talent cultivation}

AMMRA activities have developed from initial rudimentary communications and information exchanges to advanced educational events and programs to foster collaboration and facilitate active use of mouse resources in the region (as listed in Table 2).

CARD has started a series of workshops in collaboration with the Jackson Laboratory to share knowledge and techniques of mouse reproductive technology through lectures, demonstrations, and training. The technologies have contributed to the reduction of live animals to be used and research projects as well as for the efficient management and operation of animal facilities. The Japan Mouse Clinic at RIKEN BRC has provided intensive training courses on RIKEN Modified-SHIRPA for other Asian colleagues to establish phenotyping pipelines of mouse clinics. NLAC activities have focused on pathology and phenotyping in rodents, including an advanced "Rodent Pathology Phenotyping Workshop". The target for participants were veterinarians, pathologists, and scientists aiming to gain expertise in rodent pathology and diagnostics relevant to diverse translational research areas.

The important mission of other educational programs jointly held by AMMRA members has been to cultivate young talents who will use mouse resources in future and provide opportunities to mutually exchange, advise and inspire ideas among graduate students, young scientists and experts in the field and infrastructure organizations.

\section{Future perspective}

The dramatic increase in funding to develop novel drugs and vaccines to combat the current COVID-19 pandemic clearly demonstrates how as a research tool, animal models continue to be a crucial tool for the study of disease and therapeutic development. It is our belief among AMMRA members that generating and sharing novel mouse models should be a long-term program for scientific and pharmaceutic communities. Specifically, we foresee the following areas will require significant support in the near future:

(1) models carrying mutations (mostly point mutation) discovered in clinic genetics research. These models will be useful to facilitate the gene therapy and drug development for rare diseases;

(2) humanized mouse models carrying druggable human genes. These models are heavily required for testing the efficacies of antibody drugs, vaccines, and cell therapies (such as CAR-T therapy);

(3) disease models with real-world genetic diversity. The current models are mostly generated in the inbred background of the classical laboratory mice, represented by C57BL/6, genomes of which were derived from a relatively small gene pool of the Western European subspecies, Mus musculus domesticus. A lack of genome diversity could be the key reason for the misleading high successful rate for preclinic studies of these lead compounds. The loosing safeguard on preclinical efficacy and toxicity is one of the key factors leading to high failure rate of phase $2 / 3$ clinical trials, in which the potential new drugs were tested on cohorts with broad genome compositions. Collaborative cross strains have been extremely helpful, though new strategies or technologies are desperately needed for introducing genome diversity of subspecies into laboratory mice;

(4) models created by inoculating patient's pathogenetic or conditional microbiome onto germ-free mice. These mice will be crucial not only for understanding the function of these microbiome but for promoting the development of new disease therapies, the pathogenesis of which are influenced by microbiome.

We strongly advocate for respective national governments to support the establishment of research programs in these fields. Meanwhile, AMMRA will continuously work with the international mouse resource and phenotyping communities to encourage the sharing of these models and related information. 
Table 2 Educational Programs by AMMRA member organizations

\begin{tabular}{|c|c|c|c|c|}
\hline Year & Organizer & Conference name and topic & Venue & Region \\
\hline 2008 & CARD, KRIBB & $\begin{array}{l}\text { CARD-KRIBB Reproductive Technol- } \\
\text { ogy Workshop }\end{array}$ & KRIBB & Korea \\
\hline 2009 & NLAC, Johns Hopkins University & $\begin{array}{l}\text { Rodent Pathology Phenotyping Work- } \\
\text { shop }\end{array}$ & Academia Sinica & Taiwan \\
\hline 2010 & CARD, BRC A*STAR & $\begin{array}{l}\text { CARD-BRC Reproductive Technology } \\
\text { Workshop }\end{array}$ & BRC A*STAR & Singapore \\
\hline 2011 & NLAC, Johns Hopkins University & $\begin{array}{l}\text { Rodent Pathology Phenotyping Work- } \\
\text { shop }\end{array}$ & Academia Sinica & Taiwan \\
\hline 2012 & $\begin{array}{l}\text { RIKEN BRC, Nanjing University } \\
\text { MARC }\end{array}$ & $\begin{array}{l}\text { The 1st RIKEN BRC-Nanjing Univer- } \\
\text { sity MARC International Short Sum- } \\
\text { mer Course of the Mouse }\end{array}$ & RIKEN BRC & Japan \\
\hline 2012 & CARD, NLAC & $\begin{array}{l}\text { CARD-NLAC Reproductive Technology } \\
\text { Workshop }\end{array}$ & NLAC & Taiwan \\
\hline 2013 & $\begin{array}{l}\text { RIKEN BRC, Nanjing University } \\
\text { MARC }\end{array}$ & $\begin{array}{l}\text { The 3rd RIKEN BRC-Nanjing Univer- } \\
\text { sity MARC International Summer } \\
\text { Intensive Course of the Mouse }\end{array}$ & RIKEN BRC & Japan \\
\hline 2013 & $\begin{array}{l}\text { Nanjing University MARC, RIKEN } \\
\text { BRC }\end{array}$ & $\begin{array}{l}\text { The 2nd Nanjing University MARC- } \\
\text { RIKEN BRC International Summer } \\
\text { Intensive Course of the Mouse }\end{array}$ & MARC & China \\
\hline 2013 & CARD & $\begin{array}{l}\text { CARD-NIFDC Reproductive Technol- } \\
\text { ogy Workshop }\end{array}$ & $\begin{array}{l}\text { The National Institute for Food and } \\
\text { Drug Control (NIFDC) }\end{array}$ & China \\
\hline 2013 & CARD & $\begin{array}{l}\text { CARD-CNB Reproductive Technology } \\
\text { Workshop }\end{array}$ & $\begin{array}{l}\text { National Centre for Biotechnology at } \\
\text { Spanish National Research Council } \\
\text { (CNB-CSIC) }\end{array}$ & Spain \\
\hline 2014 & Phenomics Australia & $\begin{array}{l}\text { AMMRA-AMPC Student Workshop } \\
\text { "Toward precision medicine, pheno- } \\
\text { typing human disease in mice" }\end{array}$ & The Australian National University & Australia \\
\hline 2014 & CARD & $\begin{array}{l}\text { CARD-RPCI Reproductive Technology } \\
\text { Workshop }\end{array}$ & Roswell Park Cancer Institute & USA \\
\hline 2014 & NLAC, Jax Laboratory & $\begin{array}{l}\text { Strategies for modeling human disease } \\
\text { in the laboratory mouse }\end{array}$ & Academia Sinica & Taiwan \\
\hline 2015 & $\begin{array}{l}\text { Nanjing University MARC, RIKEN } \\
\text { BRC }\end{array}$ & $\begin{array}{l}\text { The 4th Nanjing University MARC- } \\
\text { RIKEN BRC International Short Sum- } \\
\text { mer Course of the Mouse }\end{array}$ & MARC & China \\
\hline 2015 & CARD, KRIBB & $\begin{array}{l}\text { CARD-KRIBB Reproductive Technol- } \\
\text { ogy Workshop }\end{array}$ & KRIBB & Korea \\
\hline 2016 & $\begin{array}{l}\text { RIKEN BRC, Nanjing University } \\
\text { MARC }\end{array}$ & $\begin{array}{l}\text { The 5th RIKEN BRC-Nanjing Univer- } \\
\text { sity MARC Mouse Resource Work- } \\
\text { shop "Biological Imaging of Disease } \\
\text { Models" }\end{array}$ & RIKEN BRC & Japan \\
\hline 2016 & CARD & $\begin{array}{l}\text { CARD-IP Reproductive Technology } \\
\text { Workshop }\end{array}$ & Institute Pasteur & France \\
\hline 2017 & $\begin{array}{l}\text { KMPC, Nanjing University MARC, } \\
\text { RIKEN BRC }\end{array}$ & $\begin{array}{l}\text { The 6th RIKEN-MARC-KMPC Mouse } \\
\text { Workshop (Summer School) "From } \\
\text { breeding mouse to editing mouse } \\
\text { genome" }\end{array}$ & NEST Hotel, Incheon & Korea \\
\hline 2017 & CARD & $\begin{array}{l}\text { CARD-TEXAS Reproductive Technol- } \\
\text { ogy Workshop }\end{array}$ & $\begin{array}{l}\text { Texas A\&M Institute of Genomic } \\
\text { Medicine }\end{array}$ & USA \\
\hline 2018 & $\begin{array}{l}\text { Nanjing University MARC, RIKEN } \\
\text { BRC }\end{array}$ & $\begin{array}{l}\text { The 7th Sino-Japan Summer Course of } \\
\text { Genetic Mouse Models "Humanized } \\
\text { Mouse Models" }\end{array}$ & MARC & China \\
\hline 2018 & CARD & $\begin{array}{l}\text { CARD-JAX Reproductive Technology } \\
\text { Workshop }\end{array}$ & The Jackson Laboratory & USA \\
\hline 2019 & CARD & $\begin{array}{l}\text { CARD-RIKEN BDR Reproductive } \\
\text { Technology Workshop }\end{array}$ & $\begin{array}{l}\text { RIKEN Center for Biosystems Dynam- } \\
\text { ics Research }\end{array}$ & Japan \\
\hline
\end{tabular}


Table 2 (continued)

\begin{tabular}{llll}
\hline Year & Organizer & Conference name and topic & Venue \\
\hline 2019 Phenomics Australia & $\begin{array}{l}\text { The Student Workshop of Mouse Genet- } \\
\text { ics }\end{array}$ & $\begin{array}{l}\text { Walter and Eliza Hall Institute of Medi- } \\
\text { cal Research (WEHI), Melbourne }\end{array}$ \\
2019 RIKEN BRC, Nanjing University & $\begin{array}{l}\text { The 8th Japan-Sino-Korea Mouse } \\
\text { MARC, KMPC }\end{array}$ & $\begin{array}{l}\text { Resource Workshop "Precision mod- } \\
\text { eling of human diseases in mice and }\end{array}$ & \\
& cell resources" & \\
\hline
\end{tabular}

Acknowledgements CARD is supported by the Research on Development of New Drugs (Project ID: 167698659) from the Japan Agency for Medical Research and Development. Korea Mouse Phenotyping Center (KMPC) is supported by the National Research Foundation (NRF) funded by the Korean Government (Ministry of Science and ICT, NRF-2014M3A9D5A01074636, 2014M3A9D5A01074814, 2021M3H9A1030158). KRIBB is supported by KRIBB Research Initiative Program and Korean Ministry of Science and ICT (2020M3A9I6A03036066). NLAC NARLabs is supported by Ministry of Science and Technology, Taiwan. NRCMM is supported by National Resource Sharing Platform of Ministry of Science and Technology of China and the Collaborative Innovation of Industry, University, and Research Institute Major Program of Guangzhou (201604046020). RIKEN BRC has participated in the National BioResource Project of the Ministry of Education, Culture, Sports, Science and Technology (MEXT), Japan. Phenomics Australia is supported by the Australian Government through the National Collaborative Research Infrastructure Strategy (NCRIS) program. The descriptions of IDM and LAR/ CAS were obtained through personal communications (Dr. Xiaohui Wu and Dr. Yong Tian).

\section{Declarations}

Conflict of interest On behalf of all authors, the corresponding author states that there is no conflict of interest.

\section{References}

Bowl MR, Simon MM, Ingham NJ, Greenaway S, Santos L, Cater H, Taylor S, Mason J, Kurbatova N, Pearson S et al (2017) (2017) A large scale hearing loss screen reveals an extensive unexplored genetic landscape for auditory dysfunction. Nat Commun 8:886. https://doi.org/10.1038/s41467-017-00595-4

Dickinson ME, Flenniken AM, Ji X, Teboul L, Wong MD, White JK, Meehan TF, Weninger WJ, Westerberg H, Adissu H et al (2016) High-throughput discovery of novel developmental phenotypes. Nature 537:508-514. https://doi.org/10.1038/nature19356

Furuse T, Mizuma H, Hirose Y, Kushida T, Yamada I, Miura I, Masuya H, Funato H, Yanagisawa M, Onoe H et al (2019) A new mouse model of GLUT1 deficiency syndrome exhibits abnormal sleepwake patterns and alterations of glucose kinetics in the brain. Dis Model Mech 12:dmm038828. https://doi.org/10.1242/dmm. 038828

He WQ, Peng YJ, Zhang WC, Lv N, Tang J, Chen C, Zhang CH, Gao S, Chen HQ, Zhi G, Feil R, Kamm KE, Stull JT, Gao X, Zhu MS (2008) Myosin light chain kinase is central to smooth muscle contraction and required for gastrointestinal motility in mice. Gastroenterology 135:610-620

Karp NA, Mason J, Beaudet AL, Benjamini Y, Bower L, Braun RE, Brown SDM, Chesler EJ, Dickinson ME, Flenniken AM et al
(2017) Prevalence of sexual dimorphism in mammalian phenotypic traits. Nat Commun 8:15475. https://doi.org/10.1038/ncomm s15475

Kishimoto K, Tamura M, Nishita M, Minami Y, Yamaoka A, Abe T, Shigeta M, Morimoto M (2018) Synchronized mesenchymal cell polarization and differentiation shape the formation of the murine trachea and esophagus. Nat Commun 9:2816. https://doi.org/10. 1038/s41467-018-05189-2

Kobayashi N, Kume S, Lenz K, Masuya H (2018) RIKEN MetaDatabase: a database platform for health care and life sciences as a microcosm of linked open data cloud. Int J Semant Web Inf Syst 14:140-164. https://doi.org/10.4018/IJSWIS.2018010106

Liu B, Ye B, Zhu X, Yang L, Li H, Liu N, Zhu P, Lu T, He L, Tian Y, Fan Z (2020) An inducible circular RNA circKent2 inhibits ILC3 activation to facilitate colitis resolution. Nat Commun 11:4076. https://doi.org/10.1038/s41467-020-17944-5

Liu B, Liu N, Zhu X, Yang L, Ye B, Li H, Zhu P, Lu T, Tian Y, Fan Z (2021) Circular RNA circZbtb20 maintains ILC3 homeostasis and function via Alkbh5-dependent m(6)A demethylation of Nr4a1 mRNA. Cell Mol Immunol 18:1412-1424. https://doi.org/ 10.1038/s41423-021-00680-1

Lloyd KCK, Adams DJ, Baynam G, Beaudet AL, Bosch F, Boycott KM, Braun RE, Caulfield M, Cohn R, Dickinson ME et al (2020) The Deep Genome Project. Genome Biol 21:18. https://doi.org/ 10.1186/s13059-020-1931-9

Masuya H, Makita Y, Kobayashi N, Nishikata K, Yoshida Y, Mochizuki Y, Doi K, Takatsuki T, Waki K, Tanaka N et al (2011) The RIKEN integrated database of mammals. Nucleic Acids Res D. https://doi.org/10.1093/nar/gkq1078

Masuya H, Usuda D, Nakata H, Yuhara N, Kurihara K, Namiki Y, Iwase S, Takada T, Tanaka N, Suzuki K et al (2021) Establishment and application of information resource of mutant mice in RIKEN BioResource Research Center. Lab Anim Res 37:6. https://doi.org/ 10.1186/s42826-020-00068-8

Matsumura K, Seiriki K, Okada S, Nagase M, Ayabe S, Yamada I, Furuse T, Shibuya H, Yasuda Y, Yamamori H et al (2020) Pathogenic POGZ mutation causes impaired cortical development and reversible autism-like phenotypes. Nat Commun 11:859. https:// doi.org/10.1038/s41467-020-14697-z

Nakagata N (2010) Mouse Bank at CARD Kumamoto University, Japan. Interdiscip Bio Central 2(4):16.1-16.4. https://doi.org/10. 4051/ibc.2010.2.4.0016

Nakagata N, Yamamura K (2009) Activities of CARD as an International Core Center for Mouse Resources. Exp Anim 58:343-350. https://doi.org/10.1538/expanim.58.343

Niu YY, Shen B, Cui Y, Chen YC, Wang JY, Wang L, Kang Y, Zhao XY, Si W, Li W, Xiang AP, Zhou JK, Guo XJ, Bi Y, Si CY, Hu B, Dong GY, Wang H, Zhou ZM, Li TQ, Tan T, Pu XQ, Wang F, Ji SH, Zhou Q, Huang XX, Ji WZ, Sha JH (2014) Generation of gene-modified cynomolgus monkey via Cas9/RNA-mediated gene targeting in one-cell embryos. Cell 156:836-843

Qiao J, Li YS, Zeng R, Liu FL, Luo RH, Huang C, Wang YF, Zhang J, Quan B, Shen C, Mao X, Liu X, Sun W, Yang W, Ni X, Wang K, 
Xu L, Duan ZL, Zou QC, Zhang HL, Qu W, Long YHP, Li MH, Yang RC, Liu X, You J, Zhou Y, Yao R, Li WP, Liu JM, Chen P, Liu Y, Lin GF, Yang X, Zou J, Li L, Hu Y, Lu GW, Li WM, Wei

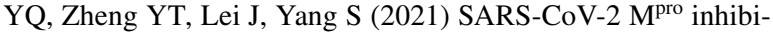
tors with antiviral activity in a transgenic mouse model. Science 371:1374-1378

Rozman J, Rathkolb B, Oestereicher MA, Schütt C, Ravindranath AC, Leuchtenberger S, Sharma S, Kistler M, Willershäuser M, Brommage $\mathrm{R}$ et al (2018) Identification of genetic elements in metabolism by high-throughput mouse phenotyping. Nat Commun 9:288. https://doi.org/10.1038/s41467-017-01995-2

Takada T, Yoshiki A, Obata Y, Yamazaki Y, Shiroishi T (2015) NIG_ MoG: a mouse genome navigator for exploring intersubspecific genetic polymorphisms. Mamm Genome 26:331-337. https://doi. org/10.1007/s00335-015-9569-8

Takeo T, Nakao S, Nakagawa Y, Sztein JM, Nakagata N (2020) Cryopreservation of mouse resources. Laboratory Animal Research, 36, Article number: 33. https://doi.org/10.1186/s42826-020-00066-w

Tanaka N, Masuya H (2020) An atlas of evidence-based phenotypic associations across the mouse phenome. Sci Rep 10:3957. https:// doi.org/10.1038/s41598-020-60891-w
Wakana S, Suzuki T, Furuse T, Kobayashi K, Miura I, Kaneda H, Yamada I, Motegi H, Toki H, Inoue M et al (2009) Introduction to the Japan Mouse Clinic at the RIKEN BioResource Center. Exp Anim 58:443-450. https://doi.org/10.1538/expanim.58.443

Wang Y, Zhu P, Wang J, Zhu X, Luo J, Meng S, Wu J, Ye B, He L, Du $\mathrm{Y}$ et al (2018) Long noncoding RNA lncHand2 promotes liver repopulation via c-Met signaling. J Hepatol 69:861-872. https:// doi.org/10.1016/j.jhep.2018.03.029

Yoshiki A, Ike F, Mekada K, Kitaura Y, Nakata H, Hiraiwa N, Mochida K, Ijuin M, Kadota M, Murakami A et al (2009) The mouse resources at the RIKEN BioResource center. Exp Anim 58:85-96. https://doi.org/10.1538/expanim.58.85

Zou Q, Wang X, Liu Y, Ouyang Z, Long H, Wei S, Xin J, Zhao B, Lai S, Shen J, Ni Q, Yang H, Zhong H, Li L, Hu M, Zhang Q, Zhou Z, He J, Yan Q, Fan N, Zhao Y, Liu Z, Guo L, Huang J, Zhang G, Ying J, Lai L, Gao X (2015) Generation of gene-target dogs using CRISPR/Cas9 system. J Mol Cell Biol 7:580-583

Publisher's Note Springer Nature remains neutral with regard to jurisdictional claims in published maps and institutional affiliations. 